\title{
Clinical Diagnosis of Pneumothorax Is Late: Use of Trend Data and Decision Support Might Allow Preclinical Detection
}

\author{
NEIL McINTOSH, JULIE-CLARE BECHER, STEPHEN CUNNINGHAM, BEN STENSON, \\ IAN A. LAING, ANDREW J. LYON, AND PETER BADGER
}

Department of Child Life and Health, University of Edinburgh, Edinburgh EH9 IUW, U.K.

\begin{abstract}
Pneumothorax in the newborn has a significant mortality and morbidity. Early diagnosis would be likely to improve the outlook. Forty-two consecutive cases of pneumothorax that developed after admission to a tertiary referral neonatal medical intensive care unit over 4 y from 1993 to 1996 were reviewed. The time of onset of the pneumothorax was determined by retrospective evaluation of the computerized trend of transcutaneous carbon dioxide $\left(\mathrm{tcpCO}_{2}\right)$ and oxygen tensions. The timing of the occurrence in the notes and $\mathrm{x}$-rays determined the time of clinical diagnosis noted at the time. The difference was the time the condition was undiagnosed. The overall mortality before discharge was $45 \%$ (19cases), four patients succumbing within $2 \mathrm{~h}$. The median time (range) between onset of pneumothorax and clinical diagnosis was $127 \mathrm{~min}$ (45-660 $\mathrm{min}$ ). In most cases, the endotracheal tube was aspirated and the transcutaneous blood gas sensor was repositioned, and in at least $40 \%$ of the cases, the baby was reintubated before the diagnosis was made. Reference centiles were constructed for level of tcpCO $\mathrm{CO}_{2}$ and slope of the trended tcpCO $\mathrm{C}_{2}$ over various time intervals (in minutes) from 729 infants from 23 to $42 \mathrm{wk}$ gestation who needed intensive care
\end{abstract}

\section{ABSTRACT}

during the first $7 \mathrm{~d}$ of life from the same time period. The 5-min tcpCO $\mathrm{O}_{2}$ trend slopes were compared in index and matched control infants. The presence of five consecutive and overlapping 5-min slopes greater than the 90th centile showed good discrimination for a pneumothorax (area under the receiver operating characteristic curve, 89\%). We concluded that 1) the clinical diagnosis of pneumothorax was late, occurring when infants decompensate; 2) trend monitoring of $\mathrm{tcpCO}_{2}$ might allow the diagnosis to be made earlier if used properly; and 3) use of reference centiles of the trended slopes of $\mathrm{tcpCO}_{2}$ might be used for automatic decision support in the future. (Pediatr Res 48: 408-415, 2000)
Abbreviations
tcpCO $\mathrm{C}_{2}$, transcutaneous carbon dioxide tension
tcpO $\mathrm{O}_{2}$, transcutaneous oxygen tension
Fio $_{2}$, fraction of inspired oxygen
ROC, receiver operating characteristic
AUC, area under the curve

A pneumothorax is a life-threatening complication of ventilatory assistance in the neonatal unit and has a high mortality $(1,2)$ and morbidity (3) Pneumothoraces are generally thought to develop rapidly. They are usually diagnosed once the infant has decompensated sufficiently to make it obvious that there is a serious clinical problem. Under these circumstances, it may be only a short period before the baby is critically ill because of the development of tension within the thoracic cavity. This problem is becoming less common, but this may mean that junior medical and nursing staff caring for these infants have become less familiar with the condition. As a consequence, the diagnosis may be made even later in the clinical course and the staff may have less skill in the emergency treatment. It is probable that the earlier a pneumothorax is drained, the less

Received April 22, 1999; accepted April 2, 2000

Correspondence: Neil McIntosh, DSc(Med), Department of Child Life and Health, University of Edinburgh, 20 Sylvan Place, Edinburgh EH9 1UW, UK.

Supported by The Wooden Spoon, The Woman and Children's Welfare Fund. damage will occur from hypoxia, hypercarbia, and venous and arterial pressure changes as a result of the raised mediastinal pressure. Early diagnosis, therefore, should be beneficial.

During the last $10 \mathrm{y}$ in our neonatal unit, we have used trend data display with a computerized cot-monitoring system (4-6). This has helped us to make the diagnosis of pneumothorax, but has also indicated that the clinical diagnosis may be late. We have analyzed our trend records to identify the likely time of onset of the air leak and have compared this with the clinical time of diagnosis. We have also analyzed our records to establish what has been done to the baby between these events.

This paper also examines levels of tcpCO $\mathrm{CO}_{2}$ in infants during the first $7 \mathrm{~d}$ of life. We define reference centiles for tcpCO $\mathrm{CO}_{2}$ and also for the trend slopes of the tcpCO $\mathrm{CO}_{2}$ during a period of time (5 min). We compare the tcpCO $\mathrm{CO}_{2}$ levels and trend slopes of an index group of 42 babies with a defined onset of pneumothorax with the centiles of the neonatal unit population and also with the 5-min slope centiles of a specific matched group of infants. 
We make conclusions about how the diagnosis of pneumothorax may be made earlier.

\section{METHODS}

\section{Infants}

Study population. The population base for this study consists of newborns receiving intensive care at the Simpson Memorial Maternity Pavilion in Edinburgh during a period of $4 \mathrm{y}$ from 1993 to 1996 . This unit routinely receives sick newborns from southeast Scotland and overflow at times of need from other areas of Scotland. All neonatal medical care is available in this tertiary referral unit except extracorporeal membrane oxygenation. Infants requiring surgery are transferred to a neighboring facility. Our indication to ventilate is either respiratory instability, manifest as inability to maintain acceptable blood gases in added oxygen, or in very immature infants, to prevent such instability.

Pneumothorax group. All babies who had pneumothorax recorded as a diagnosis during their admission to the Simpson Memorial Maternity Pavilion during the 4-y period from 1993 to 1996 were included in this study. A group of infants whose pneumothoraces occurred at least $1 \mathrm{~h}$ after arrival on the unit was used to study the relationship of their tcpCO $\mathrm{CO}_{2}$ data to the normal reference centile data. Two time points were noted in each of these infants.

Time of clinical diagnosis of pneumothorax: In our unit, it is our policy to confirm the clinical diagnosis of pneumothorax by chest $\mathrm{x}$-ray except in the very acutely deteriorating infant, in extremis, where transillumination may be used before "blind chest needling." The time of clinical diagnosis was identified from the time of the first x-ray in which a pneumothorax was present and before a thoracostomy drain was inserted. All portable $\mathrm{x}$-rays in our unit have the time they were taken written on them by the radiographer. As it takes approximately 20 min to get an urgent $\mathrm{x}$-ray done from the time of request on our unit, we subtracted 20 min from this time to give the time of clinical diagnosis. In a small minority of babies, there was no x-ray demonstrating a pneumothorax without a thoracostomy drain. In these cases, the time for clinical diagnosis was estimated from the intensive care charts indicating when a chest had been needled as an emergency and properly drained. The comments in the computerized cot-monitoring system were also helpful in these cases as they were entered by the nurse at the time.

Time of onset of pneumothorax: The probable time of onset was identified retrospectively from the trended transcutaneous gas records (viewing them back from the time of the clinical diagnosis). In each case, the onset was identified by a sharp rise in the trend $\operatorname{tcpCO}_{2}$ slope that usually occurred at the same time as a sharp but briefer fall in the tcpO $\mathrm{O}_{2}$ (before the nurse turned up the $\mathrm{FiO}_{2}$ to minimize the period of hypoxia). The time of onset of the pneumothoraces was established by the lead author from retrospective review of the tcpCO $\mathrm{CO}_{2}$ and $\mathrm{tcpO} \mathrm{O}_{2}$ traces. There is no guarantee that the onset occurred at this point, but the traces are so characteristic that all authors believe this is very likely.
Clinical events between onset and clinical diagnosis: The nursing and medical notes and the cot-monitoring system were reviewed for events between the onset time from the monitored data and the clinical time of diagnosis. Endotracheal suction is a nursing procedure and is so variably recorded that we elected not to count these as events. Reintubation in our unit is a medical procedure and is usually recorded by staff, so a review of notes and charts gives an indication of when this occurs. The repositioning of a transcutaneous combined $\mathrm{O}_{2} / \mathrm{CO}_{2}$ probe is not usually recorded, but it gives a typical picture on the trend data and these events can be accurately counted from the computer traces.

Control infants for pneumothorax group. A control infant was matched for each index pneumothorax infant. The choice was made from our database of infants receiving ventilation during the period, and each control subject was matched to the same gestational age as the index case. The control patients were further matched as closely as possible to the day of onset (postnatal age) of the pneumothorax in the index case. If multiple appropriate control subjects were available for an index case, one was chosen at random.

Data and monitoring. All infants admitted to our unit for intensive care were monitored on multichannel physiologic monitors (Hewlett Packard 78344A, South Queensferry, U.K.), and tcpO $\mathrm{O}_{2}$ and tcpCO $\mathrm{CO}_{2}$ measurements were part of the monitoring process. The combined transcutaneous electrode was used at $43.5^{\circ} \mathrm{C}$, and the site was changed routinely every $4 \mathrm{~h}$ (or earlier if there was any recording problem), with recalibration to zero $\mathrm{O}_{2}$ and known $\mathrm{CO}_{2}$ at approximately 8 -h intervals (each nursing shift). In the first week of life, attempts were made to situate the probe preductally on the upper right side of the chest, although in the smallest infants, this was sometimes impossible.

Since 1993, our intensive care monitors have been connected to a computerized monitoring system [Mary $(4,5)]$. The data on the Hewlett Packard monitor was sampled every $1 \mathrm{~s}$ by the computer and plotted as a trend on the computer screen. The individual values of each monitored channel were also saved to disk at 1 -s intervals. The data were converted automatically to a 1-min average of the 601 -s data points after $3 \mathrm{~d}$ passed. The $t \mathrm{cpCO}_{2}$ from the 1-min averaged data were the basis of this report. Arterial blood gases and $\mathrm{pH}$ were checked approximately every $4 \mathrm{~h}$ depending on the stability of the infant. Discrepancies in tcpCO $\mathrm{O}_{2}$ and arterial $\mathrm{CO}_{2}$ tension of $>1.5 \mathrm{kPa}$ warranted transcutaneous probe recalibration. Use of this system has been previously approved of by the Lothian Health Board's ethics advisory committee, who accept that the anonymous data can be used without individual family consent.

\section{Statistics}

Reference centile construction. For the centile construction, we included all infants receiving and not receiving ventilation in which we were attempting to achieve normocarbia; thus, babies with air leaks were not excluded. Infants with birth asphyxia and persistent pulmonary hypertension of the newborn were excluded as we might have been attempting to 
hyperventilate for these conditions at that time. We were not practicing permissive hypercapnia in those years. Infants requiring inotropic support were also excluded, as their transcutaneous monitoring may have been less reliable because of diminished skin perfusion. Babies were grouped by gestation and postnatal age, not by weight or respiratory problem.

Levels of tcp $\mathrm{CO}_{2}$ data: Any value $>15$ or $<2 \mathrm{kPa}$ was presumed artifact and was excluded from the analysis. These exclusion values were chosen on the basis that they were well outside the range of our experience and also by the fact that such values on the trended data streams were almost always obvious artifact. This resulted in the exclusion of a median of $7 \%$ (range, 4 to $14 \%$ ) of the data values available per infant. The major proportion of this artifact was related to probe repositionings and recalibrations, when the value falls rapidly to $<2 \mathrm{kPa}$ as the probe reads the carbon dioxide in air. A small proportion was caused by air under the probe, which gives a similar appearance to a probe change but is recurrent and short-lived. The frequency distributions of data after these exclusions were then divided into centiles by a trend analysis statistical package (Trend Analysis, Badger Design Systems, Edinburgh UK), and the Cross Graphs graphing package (Belmont Research Incorporated, Cambridge, MA, U.S.A.) was used to smooth and plot it. Smoothing of the centiles was by a kernel density function method with a 20-point neighborhood size and a 7-point bandwidth $(7,8)$.

Slope of tcp $\mathrm{CO}_{2}$ data: We also measured the centile distributions of the slopes of the carbon dioxide trend. Slopes were calculated during 5-, 10-, 15-, and 30-min periods. These were again grouped by gestation and day of life. A 5-min slope was produced by the least squares regression line calculated from five consecutive 1-min tcpCO $\mathrm{CO}_{2}$ data points. The next 5-min slope was produced by moving $1 \mathrm{~min}$ along the time series and using the next five data points (i.e. 4 min of overlapping). The frequency distribution for all the values of the 5-min slopes from all the infants was used to create the 5-min slope centiles. The 10-min slopes were produced from 10 consecutive tcp $\mathrm{CO}_{2}$ data points in the same way. The frequency distributions of data were again divided into centiles, smoothed, and plotted as above. Slopes may be positive (a rising trend) or negative, and the steeper the slope, the more rapid the change in the level. No exclusion values were used in creating the slope centiles for two reasons. First, we wished to determine the total range of slopes (whereas for the tcp $\mathrm{CO}_{2}$ levels we wished to establish a reference range excluding artifact), and second, we did not initially know which values were likely to be artifact.

The tcpCO $\mathrm{CO}_{2}$ values and $\mathrm{tcpCO} \mathrm{CO}_{2}$ trend slope values of the pneumothorax infants were compared with those observed in the control infants and in the whole population.

Comparison of the pneumothorax and control group. In each infant with a pneumothorax, 180 consecutive 1-min data points were taken from the tcp $\mathrm{CO}_{2}$ trace, 60 from before the time of onset of the pneumothorax as determined by trend monitoring (note: not the clinical diagnosis) and 120 from after the time of onset, during which time in many cases the clinical diagnosis had not been made. In the control subjects, the closest postnatal day that data were available to that of the matched index case was chosen, and a random 180 min of data were selected from that day.

The tcpCO $\mathrm{CO}_{2}$ values and 5-min tcpCO $\mathrm{CO}_{2}$ trend slope values of the infants with pneumothorax were compared with those observed in the control infants and in the whole population.

The following features of the 5-min slopes during the 180 min were compared between the index and control groups by receiver operator characteristic (ROC) curves and, when appropriate, by sensitivity and specificity analysis:

1. The maximum 5-min slopes.

2. The total time the slopes were greater than the 90th centiles.

3. The total time the slopes were greater than the 97 th centiles.

4. The number of patients and control subjects with 5-min slopes greater than the 90th centile for $>5$ min during the $180 \mathrm{~min}$.

5. The number of patients and control subjects with 5-min slopes greater than the 90th centile for $>5$ consecutive min.

The area under the curve (AUC) were calculated by the beta version for PC of the Proproc package (designed by C. Metz and B. Herman, University of Chicago, IL U.S.A.), which uses a maximum likelihood estimation of binormal ROC curves using a proper binormal model $(9,10)$. ROC plots provide a view of the whole spectrum of sensitivity and specificity because all possible sensitivity and specificity pairs for a test are graphed. The ROC plot can be regarded as a measure of the ability of a test to discriminate between the state of health (no pneumothorax) and pneumothorax (10). The $y$ axis plots the sensitivity or true-positive fraction calculated only from index subgroup [True positive/(True positive + False negative)]. The $x$ axis plots 1 - specificity or the false-positive fraction calculated only from control subgroup [False positive/(False positive + true negative)]. As true-positive and false-positive fractions are calculated from separate subgroups, the ROC plot is independent of the prevalence of the disorder. To use the test for patient management, a decision threshold must be selected. Two major elements determine which of the possible sensitivity and specificity pairs are most appropriate for a particular application of a test: 1) the relative proportions of the two states of health being discriminated, which is related to prevalence; and 2) the relative cost or undesirability of errors, i.e. false-positive and false-negative classifications balanced with the value or benefits of correct classifications.

\section{RESULTS}

Study population. Seven hundred twenty-nine infants had data available for analysis. One complete day consists of 86,400 data points. This study therefore summarizes a total of just under 200 million data points.

Study infants with pneumothorax. Seventy-eight babies were recorded as having a pneumothorax in our database and 23 separately as having other air leaks: only the infants with pneumothoraces were studied. Thirty-six infants were excluded from the study: 10 babies were admitted from referring hospitals and three from the postnatal wards or labor ward of our own hospital already with a pneumothorax present. These were excluded as it was impossible to be clear about the 
preceding clinical events and because there were no monitoring data available. Thirteen additional infants had no computer monitoring data, five had $\mathrm{x}$-rays that were lost or notes that were not clear on the time of clinical onset. A further two preterm twins were excluded as they were monitored only by oxygen saturation (no $\mathrm{CO}_{2}$ probes available) and one when no pneumothorax could be identified either in the notes or on the x-rays (a presumed misclassification in our database). Finally, one hydropic infant that required peritoneal drainage and one infant that required lobectomy for cystic adenomatoid malformation were excluded.

This left 42 babies with $\mathrm{x}$-rays indicating the time of clinical diagnosis and trend records of tcpCO${ }_{2}$ and tcpO $\mathrm{O}_{2}$ that allowed review of the likely time of onset. The basic data of these infants has been seen by the referees and editors and is available from the lead author.

Timings of pneumothorax. The timing of the clinical diagnosis of each pneumothorax was easily established from the $\mathrm{x}$-rays, each of which had the time of taking recorded on it.

Figure 1 shows how the time of onset of the pneumothorax was identified using a rise in tcpCO ${ }_{2}$, usually associated with an acute fall in the tcpO $\mathrm{O}_{2}$ as in this representative example. The trend tcpCO $\mathrm{CO}_{2}$ levels of the 42 individual infants are shown in Fig. 2 in an attempt to indicate the common nature of the tcpCO $\mathrm{C}_{2}$ trend. We have plotted $1 \mathrm{~h}$ of trend data before our identified time of onset and $2 \mathrm{~h}$ after (except in cases 3, 34, 35, and 39, who died before this). In three cases (patients 26, 33, and 36) the trend in transcutaneous carbon dioxide is not particularly convincing from zero time, but in these cases a sudden fall in the tcpO $\mathrm{O}_{2}$ helped us to identify the time of onset. (The tcpO $\mathrm{O}_{2}$ from $15 \mathrm{~min}$ before to $15 \mathrm{~min}$ after the time of onset in all 42 cases is shown in Fig. 3). Fifteen cases had their pneumothorax drained within the 2-h period, and this is obvious on the trend traces of seven cases (Fig. 2, patients 5, 6, 9, $14,24,28$, and 32). The downward trends seen in traces from patients 4, 8, 17, 18, 20, 21, 23, 25, 37, 40, and 42 (Fig. 2) were not related to drainage of the pneumothorax but to other

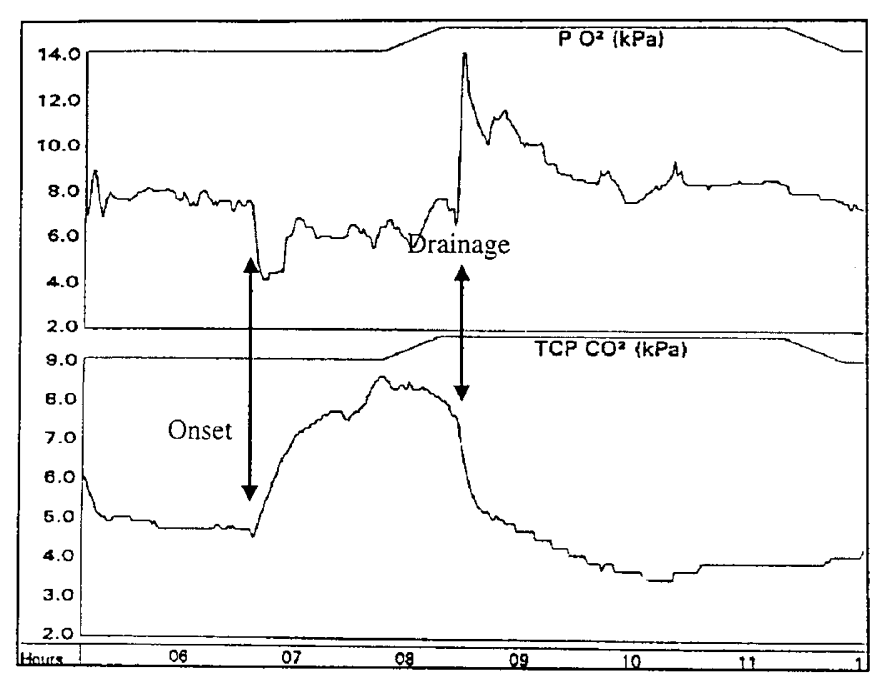

Figure 1. Seven hours of trend $\mathrm{tcpO}_{2}$ and $t c \mathrm{CO}_{2}$ data in a baby who developed a pneumothorax at approximately 0635 , illustrated by sharp fall in tcpO $\mathrm{O}_{2}$ and rise in $\mathrm{tcpCO}_{2}$. Tube thoracostomy at approximately 0830 relieves the problem.

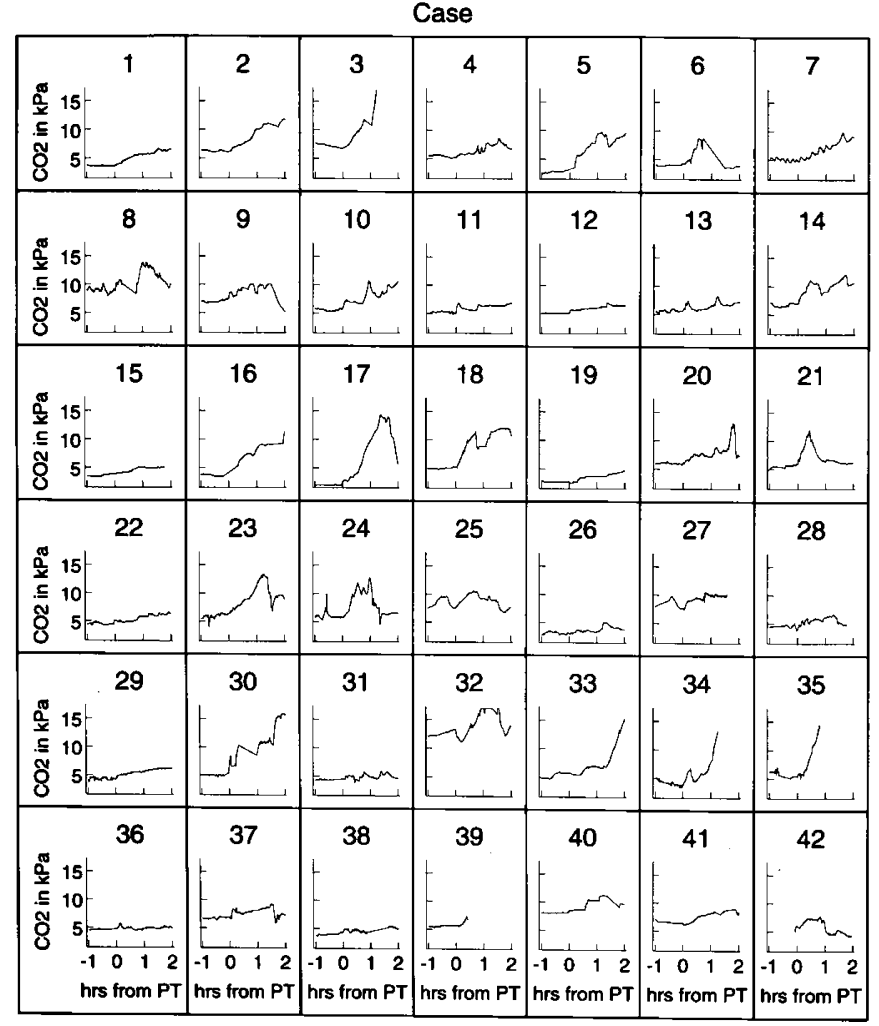

Figure 2. Trend of tcpCO $\mathrm{C}_{2}$ in 42 cases of pneumothorax. In each case, $1 \mathrm{~h}$ of trend tcpCO $\mathrm{CO}_{2}$ is plotted before the onset and $2 \mathrm{~h}$ after the onset. Onset is defined in the text.

manipulations such as increasing ventilator pressures or rates, hand-bagging, or endotracheal suction.

tcpCO $\mathrm{O}_{2}$ at time of onset. Not only does Figure 2 show the nature of the tcpCO $\mathrm{C}_{2}$ trend, it also demonstrates that a number of infants experienced their pneumothoraces when their tcpCO $\mathrm{C}_{2}$ was lower than that usually accepted. Nine cases occurred with a tcpCO $\mathrm{CO}_{2}<4 \mathrm{kPa}$ and three cases (patients 5, 17, and 19) when the tcpCO ${ }_{2}$ was $<3 \mathrm{kPa}$. Although we do not have concurrent arterial $\mathrm{pCO}_{2}$ levels in these cases, it is unusual to find a discrepancy of $>1.5 \mathrm{kPa}$ between the tcpCO and arterial levels, and when this happens the probes are recalibrated. Note that all the tcpCO $\mathrm{C}_{2}$ values on case 1 in Figure 2 are within an acceptable range. It is the change in the slope that indicates the accruing problem.

Events in the time between onset and diagnosis. Reintubation was often (although not always) recorded either in the notes or charts by medical or nursing staff, and review of these gave an indication of when this occurred; the number of times (median, 1; range, $0-2$ ) was almost certainly an underestimate. There was a median of 1 (range, $0-5$ ) probe change. One baby had his probe repositioned five times as the staff in charge failed to believe the trend level. It can be seen easily from the traces on Figure 2 that the tcpCO $\mathrm{CO}_{2}$ has not been improved $2 \mathrm{~h}$ after the onset in infants $1,2 \mathrm{~d}, 5 \mathrm{~d}, 7 \mathrm{~d}, 10 \mathrm{~d}, 11,12,13 \mathrm{~d}, 14 \mathrm{~d}$, $15,16,19,22,27 \mathrm{~d}, 29,30$, and 33 . In cases labeled "d" this is despite drainage being initiated within this period. The median time between the time of onset and diagnosis was $127 \mathrm{~min}$ (range, 45-660 $\mathrm{min}$ ). 


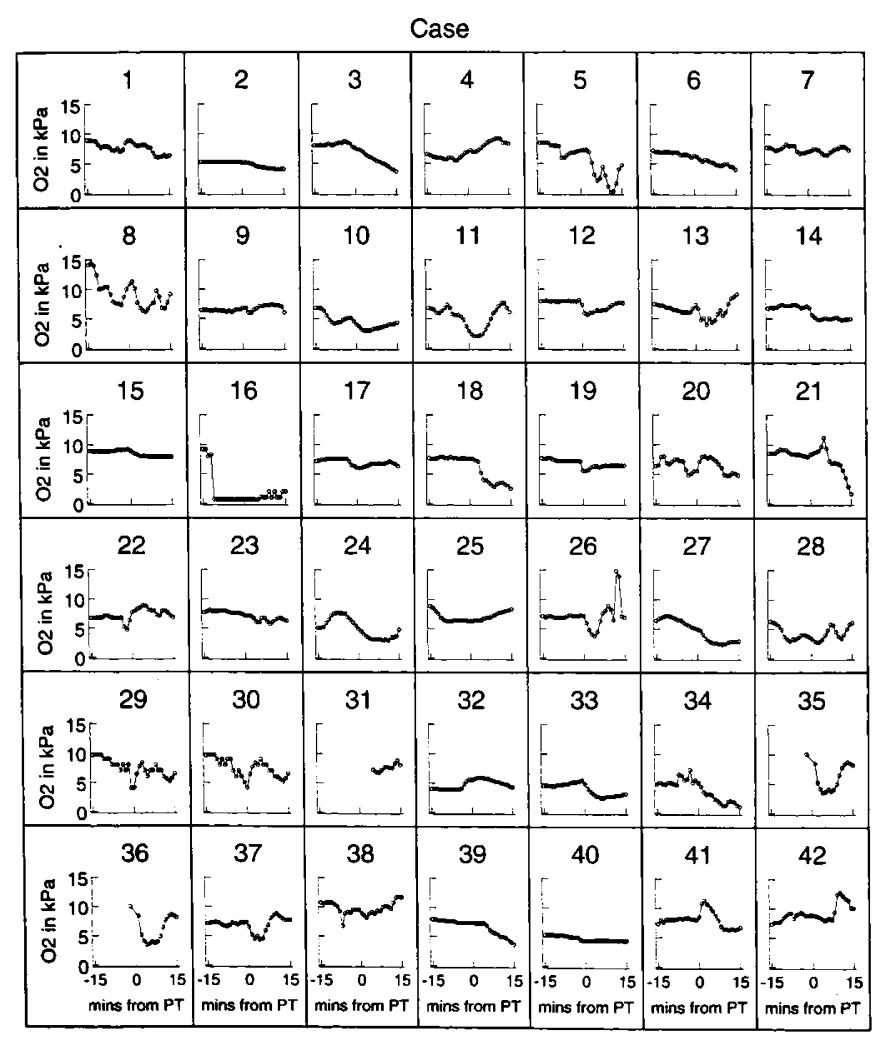

Figure 3. Trend of tcpO $\mathrm{O}_{2}$ in 42 cases of pneumothorax. In each case, $15 \mathrm{~min}$ of trend $\mathrm{tcpO}_{2}$ is plotted before the onset and $15 \mathrm{~min}$ after the onset. Onset is defined in the text.

Outcome. Nineteen of these 42 infants died before discharge from the neonatal unit and four within $2 \mathrm{~h}$ of onset. Although these infants generally represent the extremely immature, it is noteworthy that one infant was of $3 \mathrm{~kg}$ birthweight, an infant with a fatal inborn error of metabolism.

Reference centile group. Smoothed centiles of the raw tcpCO $\mathrm{C}_{2}$ data with artifact excluded are shown in Figure 4. These data are available as a table from the lead author. The widest distribution was observed in the most immature infants during the first $24 \mathrm{~h}$ of life. This probably reflected the instability of these infants, particularly on admission and before ventilation had been effected with close knowledge of blood gas status.

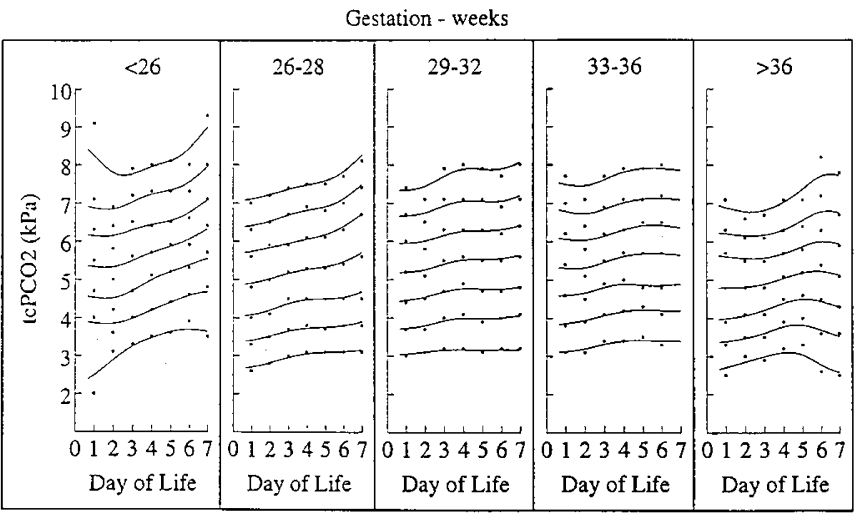

Figure 4. Reference centiles (3rd, 10th, 25th, 50th, 75th, 90th, and 97th) of tcpCO $\mathrm{C}_{2}$ with gestation and postnatal day using infants who survived to discharge without inotropic support.

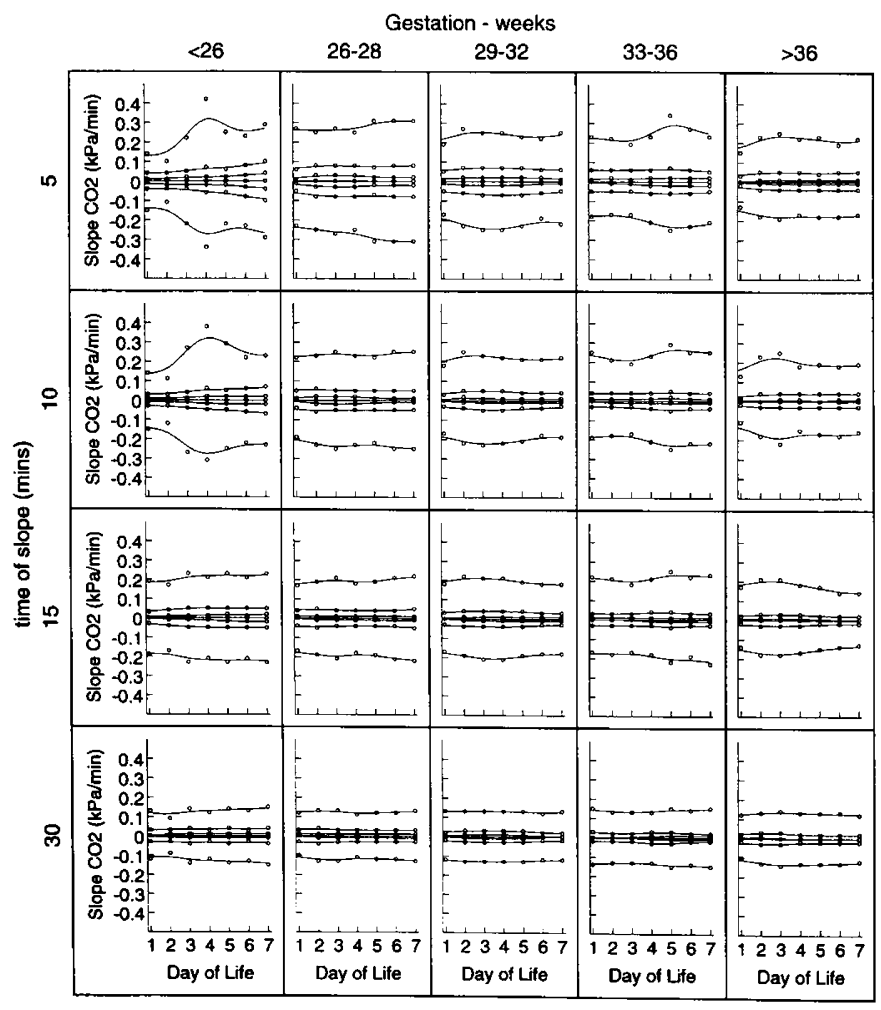

Figure 5. Reference centiles (3rd, 10th, 25th, 50th, 75th, 90th, and 97th) for slopes of tcpCO $\mathrm{CH}_{2}$ with gestation and postnatal day. The slope is calculated during the time period concerned using the least squares regression method. Slope durations: 5-, 10-, 15-, and 30-min.

Stability of the tcpCO $\mathrm{C}_{2}$ trend was measured by examining the slopes during a 5-, 10-, 15-, and 30-min time period. Figure 5 shows the centiles of these slopes. It can be seen that the spread of the centiles of the slopes changes with gestation and postnatal age. The majority of the slopes less than the 10th centile and greater than the 90th centile are related to probe changing and recalibration as the values at these times were not excluded from the slope calculations.

Pneumothorax data compared with centiles. Table $1 \mathrm{com}-$ pares the time taken in the pneumothorax cases for the tcpCO $\mathrm{CO}_{2}$ levels and the tcpCO $\mathrm{C}_{2}$ trend slopes measured during 5, 10, and 15 min to rise to greater than the 90th centiles of our reference data. In each case, the 90th centile was taken appropriately for the infant's gestation and the postnatal age. In 10 infants

Table 1. Time taken for each variable to reach more than the 90th centile after the occurrence of a pneumothorax

\begin{tabular}{|c|c|c|c|c|}
\hline Measurements & CORW & COSL005 & COSL010 & COSL015 \\
\hline Cases (42 possible) & $32 *$ & $38 \dagger$ & $37 \dagger$ & $37 \dagger$ \\
\hline Median time (min) & 23 & 4 & 5 & 6 \\
\hline Quartiles (min) & 10,78 & 2,14 & 3,16 & 3,18 \\
\hline$p$ (Mann-Whitney $U$ ) & \multicolumn{2}{|c|}{.009} & \multicolumn{2}{|c|}{.57} \\
\hline
\end{tabular}

Abbreviations: CORW, raw carbon dioxide level; COSL005, 010, 015 are $5-, 10-$, and 15-min slopes of carbon dioxide, respectively. ${ }^{*}$ The difference between possible and actual cases is related to six cases being excluded as greater than 90th centile before the onset and four excluded as they never reached the 90th centile before treatment. $\dagger$ The difference between possible and actual is related to the cases being excluded because the transcutaneous electrode had been removed for recalibration making the slope calculation impossible. Stated $p$ values are comparisons between adjacent columns. 
(24\%), the tcpCO $\mathrm{C}_{2}$ level itself was of no diagnostic value as in six cases it was above the 90th centile for many hours before the pneumothorax onset and in another four cases it never rose to the 90th centile before effective treatment. In a further 17 cases $(40 \%)$, the tcpCO $\mathrm{C}_{2}$ had not risen to more than the 90th centile $1 \mathrm{~h}$ after the onset of pneumothorax. In our experience, slopes greater than the 90th centiles would only be seen after a transcutaneous probe has been repositioned, and as the tcpCO $\mathrm{CO}_{2}$ is increasing to the normal level after this. The tcpCO $\mathrm{O}_{2}$ trend slopes are much more sensitive than the levels, taking a median time of 4,5 , and 6 min to become greater than the 90th centile of 5-, 10-, and 15-min slopes, respectively, whereas it takes a median time of 23 min for the tcpCO $\mathrm{C}_{2}$ level to get this high. It was not possible to use the tcpCO $\mathrm{C}_{2}$ trend slopes in four or five infants (depending on the slope duration), in each case because the probe had been removed for recalibration.

Comparison of pneumothorax and control data. Table 2 shows the true positive and false negative numbers on the index group and the false positive and true negative numbers on the control group with different 5-min slope variables. The sensitivity and specificity and the AUC are also shown. The AUC shows that all the comparisons are good at discriminating positive from negative cases but that the best test is probably the presence of five consecutive 5-min slopes greater than the 90th centiles (AUC, 89\%; Fig. 6). Other ROC plots are shown in Table 2.

\section{DISCUSSION}

The development of a pneumothorax with ensuing hypoxia and hypercapnia is a potentially life-threatening event, and $45 \%$ of the infants in this series died before discharge from the neonatal unit. Four infants died acutely, directly as a result of the air leak or its treatment. Our mortality is similar to that reported during the last $20 \mathrm{y}$ for small preterm infants $(1,2)$. Even if not fatal, the morbidity is probably significant. In the immature infant, the combination of hypercapnia leading to increased cerebral blood flow and the venous and arterial pressure changes consequent to mediastinal shift must predispose to cerebral hemorrhage. The association of air leaks with the more severe grades of periventricular hemorrhage has been previously noted in the preterm infant (3).

It is not clear from the literature how many pneumothoraces are rapidly progressing and compromising and how many are self-healing, although the use of positive-pressure ventilation must make spontaneous resolution less likely. Currently, diagnosis rests on clinical acumen $(11,12)$ backed up by radiology

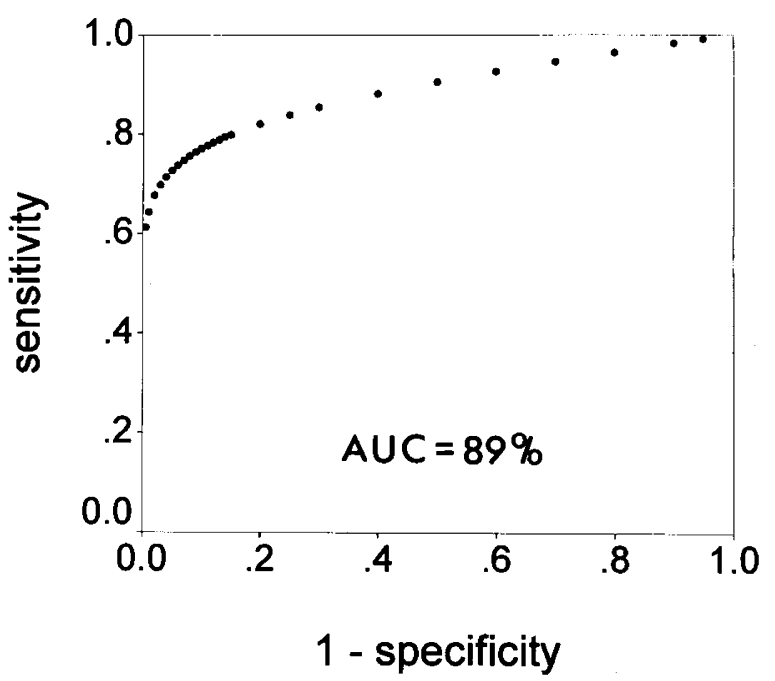

Figure 6. ROC curve for five consecutive 5-min tcpCO $\mathrm{CO}_{2}$ slopes greater than the 90th centile (see text).

(11-13). Although transillumination is quite commonly used in some units for diagnosis $(14,15)$, the use of intrathoracic pressure changes (16) and transthoracic impedance (17) are research techniques that have not been generally used. In emergency circumstances, chests undergo needle aspiration empirically.

In our own hospital, we have always insisted on an x-ray to make the diagnosis unless the baby is in extremis, but the emergency radiographer covers not only the neonatal intensive care unit but also other intensive care units and the emergency room, so an x-ray may be delayed. Many units use transillumination to make the diagnosis, only confirming the thoracostomy tube position with an x-ray. It is recognized that there is a significant false-negative and, more worrisome, false-positive rate associated with this method (15). In our view, the diagnosis of pneumothorax by transillumination and placement of thoracostomy tube is self-fulfilling, with no way of recording false positives caused by pulmonary interstitial emphysema or consolidation and collapse of the opposite lung.

We have two concerns about this review of our practice. First, even with our ability to display trends of physiology, our diagnosis sometimes seems very late. Given that the rising tcpCO $\mathrm{C}_{2}$ pattern could be from a blocked or partially blocked endotracheal tube, it is possibly reassuring that all of these babies had their endotracheal tubes suctioned out, although there are data suggesting that endotracheal suction itself can cause air leak $(18,19)$. We have no way of knowing exactly how often suction occurred in our cohort as it is only variably

Table 2. Pneumothorax: diagnostic accuracy of 5-min slope characteristics

\begin{tabular}{|c|c|c|c|c|c|c|c|c|c|}
\hline & $\begin{array}{c}\text { True Pos } \\
\text { a }\end{array}$ & $\begin{array}{c}\text { False Pos } \\
\text { b }\end{array}$ & $\begin{array}{c}\text { False Neg } \\
\mathrm{c}\end{array}$ & $\begin{array}{c}\text { True Neg } \\
\text { d }\end{array}$ & $\begin{array}{l}\text { Sensitivity } \\
a /(a+c)\end{array}$ & $\begin{array}{l}\text { Specificity } \\
\text { d/(b + d) }\end{array}$ & $\begin{array}{c}\text { PPV } \\
a /(a+b)\end{array}$ & $\begin{array}{c}\text { NPV } \\
d /(c+d)\end{array}$ & $\begin{array}{l}\text { ROC } \\
\text { AUC }\end{array}$ \\
\hline Maximum slope & & & & & & & & & $81 \%$ \\
\hline Slope $>90$ th centile $>0$ min & 41 & 37 & 0 & 3 & $100 \%$ & $8 \%$ & $53 \%$ & $100 \%$ & $82 \%$ \\
\hline Slope $>97$ th centile $>0 \mathrm{~min}$ & 31 & 14 & 10 & 26 & $76 \%$ & $65 \%$ & $69 \%$ & $72 \%$ & $81 \%$ \\
\hline Slope $>90$ th centile $>5$ min (total) & 40 & 27 & 1 & 13 & $98 \%$ & $33 \%$ & $60 \%$ & $93 \%$ & $76 \%$ \\
\hline Slope $>90$ th centile $>5 \min ($ consecutive $)$ & 33 & 5 & 9 & 35 & $79 \%$ & $88 \%$ & $87 \%$ & $80 \%$ & $89 \%$ \\
\hline
\end{tabular}

$\mathrm{PPV}$, positive predictive value, NPV, negative predictive value. 
recorded. Sadly however, it would seem that our staff, seeing the rising trend of $\mathrm{tcpCO}_{2}$, are then more likely to reposition and sometimes even recalibrate the electrode than to postulate the presence of a pneumothorax. Although the tcpCO $\mathrm{CO}_{2}$ probe may not accurately record the absolute level of arterial carbon dioxide tension, the trend is unlikely to be wrong (20), and in our experience, the drift in the newer combined electrodes is small. We would believe that repositioning for reasons other than those associated with the probe temperature or because of air under the electrode would be inappropriate. It also seems to be common to reintubate in case there is blockage of the endotracheal tube. This is not inappropriate as in both cases there is a rise in the tcpCO ${ }_{2}$, but it reinforces that a better clinical way of diagnosing an air leak within the neonatal unit would be useful. Our second concern in this study is that in some infants the tcpCO $\mathrm{C}_{2}$ levels have been very low at the time of the pneumothorax. This implies that our ventilator management may be less than ideal and we may be ventilating some infants too fast or at an inappropriate point on their pressurevolume curves leading to the air leak.

The use of trended tcpO $\mathrm{O}_{2}$ does not give the same information regarding either tube blockage or pneumothorax. It is intrinsically a much more variable measure, and with a fall of any significance, the attending nurse is likely to raise the $\mathrm{Fio}_{2}$ such that any trend will be very short-lived.

When the diagnosis of pneumothorax is confirmed, there is usually an amount of frenetic activity to drain the accumulated air. During this time the baby is unstable and during the thoracostomy procedure may become even more so, sometimes because of lack of appropriate analgesia for the procedure, which should be given unless faced with imminent demise of the infant (13). Early diagnosis would give more time for effective treatment, possibly before irreversible damage is done. But as pneumothoraces become less common, partly from better ventilators and partly from better ventilation techniques, the ability of staff to diagnose them clinically is likely to become less good. Since Ogata et al. (1) first recorded the changes in blood gases and $\mathrm{pH}$ with a pneumothorax, they have been well accepted, but the speed of onset of the changes and their sensitivity and specificity are unknown.

We have used continuous transcutaneous blood gas monitoring for $8 \mathrm{y}$ and have had the advantage of being able to plot trends of physiologic data (including tcpO $\mathrm{O}_{2}$ and $\mathrm{tcpCO}_{2}$ ) on a computerized cot-monitoring system $(4,5)$ so that the trended information is available at the bedside. The use of trended tcpCO $\mathrm{CO}_{2}$ levels may assist the diagnosis (6), but a rise in tcpCO and fall in $\mathrm{tcpO}_{2}$ are not specific for a pneumothorax: such changes almost certainly occur with endotracheal tube blockage or misplacement. So far our analysis of monitored trends has been largely by the clinical impression that they create on the computer screen. The apparent slope and value of the tcpCO $\mathrm{CO}_{2}$ will depend on the horizontal time scale of the trend and the vertical definition and range given to the physiologic variable. This may partly account for the delay in diagnosis even with the display of the trends (21).

This retrospective study of trended tcpCO $\mathrm{CO}_{2}$ has shown that in these 42 cases of pneumothorax there is often a striking deviation from a steady baseline, warning of a significant respiratory problem. In such cases, if endotracheal aspiration does not rapidly rectify the blood gas, in our view an emergency $x$-ray should be requested, although many might rely on transillumination in this situation. If no diagnosis of pneumothorax is substantiated, then it is likely that there is a significant blocking or partial blocking of the endotracheal tube, and urgent consideration should be given to its replacement.

As a basis for automated computerized decision support in the future, we have created more-objective centiles for levels and slopes of tcpCO $\mathrm{C}_{2}$. The use of these centiles and particularly the slopes of the tcpCO $\mathrm{CO}_{2}$ to evaluate normality and abnormality looks promising. In particular, the AUC for 5 consecutive min with a 5 -min tcpCO $\mathrm{CO}_{2}$ slope more than the 90th centile shows good separation of pneumothorax cases and matched controls.

The prevalence of pneumothorax in our unit has now fallen to approximately $1 \%$ of babies being ventilated, so we are likely to get a significant number of false-positive alerts using the 5-min slope of the tcpCO $\mathrm{C}_{2}$. This lack of specificity has to be balanced against the probable earlier diagnosis of a condition with a considerable mortality and morbidity. The presence of a false positive may alert the physician to other important conditions such as a blocking or misplaced endotracheal tube, also important to identify. If the slopes are used as a screening test, the cost of a false-positive result depends on how confirmation of the diagnosis is established. If confirmation of the diagnosis inevitably required an $\mathrm{x}$-ray, this could be seen as being quite invasive. We would suggest that before this is ordered, it would be appropriate to suction the endotracheal tube in the baby being ventilated, and only if the problem with the tcpCO continues should an x-ray be ordered. If the babies' respiratory function and ventilator flow variables are being continually monitored, this might clarify the diagnosis and make the need for an $\mathrm{x}$-ray less appropriate.

Acknowledgments. We thank the neonatal medical and nursing staff for their dedicated help in looking after the infants described, usually some of the most difficult. C. Bass and P. Badger have helped considerably over the years with our computerized monitoring system. Dr. Jeff Millstein of Belmont Corporation gave help with Figures 2 and 3, and Dr. Isaac Kohane offered valuable advice.

\section{REFERENCES}

1. Ogata ES, Gregory GA, Kitterman JA, Phibbs RH, Tooley WH 1976 Pneumothorax in respiratory distress syndrome: incidence and effect on vital signs, blood gases and pH. Pediatrics 58:177-183

2. Yu VYH, Wong PY, Bajuk B, Szymonowitz W 1986 Pulmonary air leak in extremely low birthweight infants. Arch Dis Child 61:239-241

3. Hill A, Perlman JM, Volpe JJ 1982 Relationship of pneumothorax to occurrence of intraventricular hemorrhage in premature newborns. Pediatrics 69:144-149

4. Bass CA, Badger P, McIntosh N 1991 MARY3: a new generation computer monitoring system. In: Lafeber HN (ed) Fetal and Neonatal Physiological Measurement. Elsevier Science Publishers, Amsterdam, pp 187-190

5. McIntosh N, Ducker DA, Bass CA 1989 Mary: a computerised neonatal cot monitoring system. Int Ther Clin Monit 10:272-282

6. McIntosh N 1997 Neonatal physiological monitoring. Curr Topics Neonatol 2:85-107

7. Hastie T, Tibshirani R 1990 Generalised Additive Models. Chapman and Hall, London

8. Silverman BW 1986 Density Estimation for Statistics and Data Analysis. Chapman and Hall, London

9. Metz CE 1978 Basic principles of ROC analysis. Semin Nucl Med 8:283-298 
10. Zweig MH, Campbell G 1993 Receiver-operating characteristic (ROC) plots: a fundamental evaluation tool in clinical medicine. Clin Chem 39:561-577

11. Avery ME, Fletcher BD, Williams RG 1981 The Lung and Its Disorders in the Newborn Infant. WB Saunders, Philadelphia

12. Swischuk LE 1976 Two lesser known but useful signs of neonatal pneumothorax. Am J Roentgenol 127:623-627

13. Campbell AGM, McIntosh N 1998 Forfar and Arneil's Textbook of Paediatrics. Churchill Livingstone, Edinburgh

14. Kuhns LR, Bednarek FJ, Wyman ML, Roloff DW, Borer RC 1975 Diagnosis of pneumothorax or pneumomediastinum in neonates by transillumination. Pediatrics $56: 355-360$

15. Wyman ML, Kuhns LR 1977 Accuracy of transillumination in the recognition of pneumothorax and pneumomediastinum in the neonate. Clin Pediatr 16:323-324
16. Korvenranta H, Kero P 1983 Intraesophageal pressure monitoring in infants with respiratory disorders. Crit Care Med 11:276-279

17. Noack G, Freyschuss U 1977 The early detection of pneumothorax with transthoracic impedance in newborn infants. Acta Paediatr Scand 66:677-680

18. Anderson KD, Chandra R 1976 Pneumothorax secondary to perforation of sequential bronchi by suction catheters. J Pediatr Surg 11:687-693

19. Vaughan RS, Menke JA, Giacoia GP 1978 Pneumothorax: a complication of endotracheal tube suctioning. J Pediatr 92:633-634

20. Lewer BMF, Torrance JM, Galletly DC, Larsen PD 1988 Accuracy of transcutaneous carbon dioxide measurements. Can J Anaesth 45:186-186

21. McIntosh N, Lyon AJ, Badger P 1996 Time trend monitoring in the neonatal intensive care unit: why doesn't it make a difference? [abstract] Pediatrics 98:540 